\title{
Una nueva mirada hacia el regionalismo pictórico. La particularidad asturiana
}

\author{
Natalia Tielve Garcia *
}

\section{RESUMEN}

En el marco del problema político derivado de los regionalismos en el primer tercio del siglo $x x$, acentúa este artículo la significación que en las artes asturianas han tenido dos pintores que han llevado el regionalismo hasta sus últimas consecuencias, Evaristo Valle y Nicanor Piñole, sin olvidar los aportes de sus predecesores. La obra de todos ellos, y en especial la de los dos primeros, persigue expresarse más allá del costumbrismo romántico en asuntos o temas que reflejan un nuevo sentido de lo etnológico o de lo folklórico, alcanzando en algunos casos una significación que implica un

mayor grado de universalidad, que corre paralela a una progresiva modernización de los mercados artísticos regionales y a una paulatina renovación plástica que incorpora las corrientes europeas.

\begin{abstract}
Winthin the frame of the political problem derived from regionalisms during the first third of the 20 th. Century, this article stresses the meaning that two painters have had in the asturian arts, Evaristo Valle and Nicanor Piñole, who hav taken the regionalism to its last consequences, without forgetting the contributions from their predecesors. The work of all of them, especially the work of the first two, pursues the expression beyond the romantic customs genre in matters or themes that give a new sense to the ethnological and folkloric aspects, reaching in some cases a meaning that implies a bigger degreee of universality, that runs paralell to a progresive modernization of the regional artistic markets and to a gradual plastic renovation that incorporates the european tendencies.
\end{abstract}

* Profesora de Historia del Arte. Universidad de Oviedo. 
Una nueva mirada hacia la pintura regionalista asturiana; una mirada en la que distanciándonos de las consideraciones habituales en este tipo de análisis, queremos hacer especial incidencia en la significación que en la plástica asturiana han tenido dos pintores que han llevado el regionalismo hasta sus últimas consecuencias, Evaristo Valle y Nicanor Piñole. Dos pintores que, como veremos, practicaron un lenguaje que, si de algún modo puede caracterizarse, sea con términos como naturalidad, frescura, inmediatez y espontaneidad, sin que ello excluya una cuidada elaboración y una reflexión personal en permanente búsqueda, dentro de una imperiosa necesidad por hacer suyo todo lo perceptible hasta alcanzar una síntesis entre la observación de la naturaleza y la libre expresión de la imaginación.

Partiremos en este análisis de la consideración del regionalismo en relación con el fenómeno de la hegemonía económica y del proceso de modernización que paulatinamente iba conquistando la clase burguesa; fenómeno afianza sus propios caracteres a partir de la crisis del 98 y sus secuelas, momento en el que se revela, a un mismo tiempo, la debilidad representativa del turno de partidos y la batalla del proteccionismo alcanza unas cotas significativas. Ya la etapa histórica coincidente con la Restauración de Canovas había implicado, al lado de otros aspectos, un fortalecimiento de las oligarquías regionales. De ahí que el problema político derivado de los regionalismos se plantease durante estos años con mayor crudeza en las diversas regiones españolas y, entre ellas, en la asturiana.

Ante este panorama, el regionalismo pictórico astur se encontraba directamente relacionado con el sentimiento de regeneración que dominaba la mentalidad española del momento ${ }^{1}$. En el fondo, perseguía una renovación ética y social que, en el terreno de las actividades artísticas, trataba de expresarse más allá del costumbrismo romántico en asuntos o temas que reflejasen un nuevo sentido de lo etnológico o de lo folklórico. De hecho, la infraestructura socioeconómica española era propicia para el desarrollo de este esquema de arte regionalista. El centralismo borbónico había concedido el poder y la administración al centro. En aquellas regiones donde la fuerza económica era pujante, como eran los casos catalán y vasco, el regionalismo se oponía infraestructuralmente al centralismo. Mientras, en ámbitos como el asturiano, en donde la fuerza era menor y dependiente, se planteaba un modelo regionalista de índole

1 En Uría González, J. y otros: Asturias y Cuba en torno al 98. Labor, Oviedo, 1994, págs. 169 yss. 
fundamentalmente superestructural. De tal modo, se ponía en la provincia de manifiesto la independencia folklórica y costumbrista, para ocultar la dependencia económica y política.

En relación con estas circunstancias los principios que alentaban al régimen de la Restauración pueden ser advertidos de un modo significativo en esta región norteña ${ }^{2}$. Nos referimos, por una parte, a una constante llamada a la regeneración del país a fin de reconquistar las fuerzas que le eran vitales para su desarrollo económico. Por otro lado, el ejercicio del poder mediante el turno de partidos, en un intento de suprimir las luchas políticas que tanto daño habían causado en decenios precedentes y que ahora eran convertidas en un diálogo entre las dos grandes fuerzas que representaban a la inmensa mayoría de la opinión pública. Habida cuenta estas reveindicaciones en la esfera de lo político se constata en la vida asturiana un significativo predominio de los conservadores sobre los liberales a la hora de ejercer el poder.

Al propio tiempo, desde el punto de vista económico y demográfico, la región experimentaba un notable crecimiento, especialmente vinculado a sus áreas urbanas. En arreglo a las diferencias económicas que estas circunstancias favorecían se estructuraba su sociedad, de manera que una floreciente burguesía urbana, vinculada a las actividades mercantiles e industriales, afianzaba su preponderancia, al tiempo que el proletariado industrial y minero crecía en importancia y en fuerza. Del enfrentamiento entre ambos grupos habría de partir una escalada de agitación social que encontraba su culminación en los sucesos revolucionarios que, en el cuarto decenio del siglo, convulsionarían a la región. Paralelamente se desarrollaba un movimiento regeneracionista burgués orientado hacia la potenciación de los intereses y las realidades sociales de la provincia, frente a la estructura vacía del poder central.

Con todo, la región trata de hacer demostración, en el contexto de la época del cambio de siglo y sirviéndose de todos los medios a su alcance, de su preparación para desempeñar un papel importante en el concierto económico, cultural y político del país. El arte, fundamentalmente en su vertiente pictórica, se convierte, en cierto modo, en un vehículo de expresión capaz de dar a conocer al resto de la nación las peculiaridades y los avances regionales. Pero este sentimiento regeneracionista se traducía al mismo tiempo en una búsqueda de las raíces que habían fundamentado la escuela pictórica española. Se estimaba como un arte de pura raza, cuyos fundamentos se localizaban en los pintores clásicos, en Velázquez, en El

2 Ver MaIner, J.C.: Regionalismo, burguesía y cultura. Guaro, Zaragoza, 1982, págs. 14. 
Greco, en Murillo, en Zurbarán o en Goya. La historiografía artística de la época, la intelectualidad y los sectores de la plástica con deseos de renovación, encontraban en estos maestros clásicos una modernidad esencial sobre la que se juzgaba factible basar la modernización de la pintura española contemporánea de una manera eficaz. La recurrencia al pasado de la castiza escuela española implicaba un proceso de innovación y de cambios realizado de manera mesurada, sin bruscas alteraciones y exento, además, de todo desarraigo puesto que se encontraba fundamentado en los propios orígenes.

Va a ser sobre todo en las producciones desarrolladas a partir del desastre del 98 y hasta los años veinte, donde mejor se aprecie la mezcla de regionalismo, casticismo y conciencia social ${ }^{3}$. Se afianza entonces la paulatina modernización de los mercados artísticos regionales, los cuales proporcionan popularidad y ventas a la línea de renovación plástica que incorporaba las corrientes europeas, desde el impresionismo al surrealismo, y cuyo apogeo se producía, no obstante, con un considerable retraso con respecto al ámbito internacional.

Géneros como el del paisaje o el de el cuadro de costumbres convertían al propio medio asturiano en protagonista principal de la creación pictórica. Entre los plásticos asturianos cultivadores de esta temática, sobresalen varios nombres, como el de Luis Menéndez Pidal, quien puede ser considerado como uno de los grandes patriarcas de la escuela pictórica astur. Contemporáneo de pintores como Pradilla o Villegas, significó Pidal en su tiempo un sano deseo de apartarse de la plástica retórica y vacía de los lienzos históricos - la estética oficial imperante- para buscar en sus obras un contenido más humano, una intimidad delicada que aparecía revestida con técnica realista aprendida en la mejor escuela española. Su actitud espiritual puede, en cierto modo, ponerse en conexión con la del grupo barcelonés del círculo de San Lucas, en cuanto a sus ansias comunes de servir a los ideales de serenidad y de intimismo, impregnados éstos de un sentido profundamente religioso de la vida ${ }^{4}$. De ahí la inspiración de buena parte de las producciones de Menéndez Pidal en el vivir popular y aldeano de una región, como la asturiana, que permanecía alejada de la civilización metropolitana. Al propio tiempo, destacaba Pidal como excelente paisajista. Aunque heredero de los perjuicios escolásticos respecto de la superioridad del pintor de historia y de figura,

3 En Mainer, J.C.: La Edad de Plata, Asenet, Barcelona, 1975, págs. 89 y Ss.

4 Ver Reyero, C. y Freixa, M. : Pintura y escultura en España. 1800-1910. Cátedra, Madrid, 1995, págs. 245. 
vertió su vocación de paisajista en apuntes y en estudios íntimos que realizaba para su propia satisfacción personal. Esbozos rápidos, sueltos y espontáneos estudios de paisaje que reproducen los pintorescos parajes de la fisonomía astur.

Contemporáneos a él, sobresalen nombres como los de Tomás García Sampedro y Juan Martínez Abades, una vez más interesados por la pintura campesina, por la vida aldeana de su propia región a la que viene a añadirse un anhelo paisajístico que viene a afirmarse como un intento de pintura al aire libre, lejos de las ataduras y de los convencionalismos del taller. No en balde había pasado en efímero intento por Asturias la iniciativa del maestro Casto Plasencia — del cual García Sampedro había destacado como uno de sus más fieles seguidores-, iniciativa que se había propuesto el establecimiento en la región de una escuela de paisajistas. Esta que se ha dado en Ilamar Colonia De Muros del Nalón, malograda por la muerte de Plasencia, implicó ante todo un incipiente brote independiente de impresionismo en los años finales del siglo XIX.

$Y$ es que Asturias, al igual que en general oucría en todos y cada uno de los centros artísticos finiseculares españoles, ansiaba recobrar y reforzar su identidad en la defensa de la propia imagen. En este sentido, la representación del paisaje, más o menos mistificado, se convertía en un acto de afirmación del territorio físico y cultural de la región. En Asturias, como en Galicia, en Cantabria e incluso en el País Vasco, esta reivindicación del paisaje autóctono se sitúa en el contexto de una región que se sentía relegada, afirmando con él su hermosura física y defendiendo su identidad plástica a través de su peculiar luminosidad y cromatismo, tan alejados de los esquemas castellanos y meridionales - sobrios los unos y luminosos los otros-. La pintura de paisaje adquiría un papel preponderante puesto que era éste el escenario en el que había tenido lugar el desarrollo de la tradición y de la historia de la región. La lucha entre el hombre y la naturaleza está ausente en sus representaciones, convirtiéndose el paisaje en el vehículo de una evocación poética de la realidad. Sus manifestaciones plásticas se encuentran impregnadas de bucolismo y en ellas priman los aspectos folclóricos y lo pintoresco. Son representaciones que exaltan, en buena medida, cuestiones superficiales heredadas del tipismo, aunque sin llegar a plantear los problemas de fondo de la región: la dependencia económica y cultural con respecto a la capital española.

La orientación se dirige a presentar una visión de la Asturias húmeda y nebulosa, caracterizada por las gamas cromáticas reposadas, tranquilas; por el cultivo de las tonalidades mansas en las que predominan los grises y los verdes acuosos. La niebla es uno de los ingredientes básicos 
de este tipo de creaciones; una niebla sutil, a modo de transparencia gris, diluida, azul en el cielo o verde en el mar. Sin estridencias tonales y por medio de suaves transiciones, el esmero se concentra en la captación de esa bruma que envuelve los paisajes del terruño. Son realizaciones que, en última instancia, introducen una armónica orquestación de los tonos, cargando de connotaciones emotivas y bucólicas sus impresiones. Aunque el paisaje rural, los escenarios agrestes de montaña y la marina son los favoritos, dentro del espíritu regeneracionista se incluyen también las visiones de los paisajes urbanos. No obstante, lejos del reflejo de la urbe moderna, industrial y desarrollada, se ofrece una imagen más modesta, humilde y tradicional. Una visión de un tipo de ciudad pequeña, provinciana y cargada de historia y de espíritu. Buen ejemplo es el que proporcionan las visiones de la vetusta capital de Oviedo, merced a la reproducción de sus monumentos, de sus mansiones solariegas, de la Catedral, del mercado del Fontán, de calles con alma y que se revelan como recordatorios de un tiempo mejor. Nos encontramos, por tanto, ante un modelo de ciudad monumental y con recuerdos del pasado, que, aunque sin dramas ni misterios, se encuentra fuertemente impregnada de tintes románticos.

Al propio tiempo, aunque proliferan las vistas de conjunto, de plazas, calles, encrucijadas o patios desnudos, la ciudad se presenta también como un marco para la presencia humana: las urbes, en tanto que habitáculo y escenario para el discurrir de la vida de las gentes. Resultan, en este sentido, muy escasas las representaciones de la sociedad burguesa emergente, que comenzaba a imponer su dictadura económica sobre las ciudades. Proliferan, en cambio, las representaciones de sus tipos populares, de los seres humildes y marginados, de la gran masa del pueblo llano. Los artistas, ante ello, se decantan por la representación de la vida en los pueblos pequeños, una vida que conserva las tradiciones y la religión en su estado puro, en permanente contacto con el medio natural. El discurrir del enclave rural permanece alejado de la maquinización de los núcleos urbanos, así como de todos los aspectos que se consideran capaces de acabar con el espíritu natural de las gentes. La esfera de lo religioso, además, conservaba en el ámbito campesino su aspecto más místico, más profundo e incluso ascético, manifestándose como una expresión, en cierto modo, de la continuidad histórica.

En relación con la voluntad de búsqueda y afirmación de la propia imagen y en acentuada ligazón con el género paisajístico, se producía en la pintura asturiana una revalorización de las representaciones de los seres populares de la región: del campesinado, de los hombres y mujeres del 
mar y de la mina ${ }^{5}$. Los artífices de la plástica se esfuerzan por hacer ver que la pintura regionalista que practican no puede ser considerada como la expresión sinónima de un arte desprovisto de virtudes plásticas; de un arte atento exclusivamente a la reproducción y exageración de tipismos afectados, construidos dentro de un academicismo trasnochado. Por el contrario, sus manifestaciones pretenden coordinar sus ansias de novedad con un encuadre regional y español, en un momento en el que la escuela madrileña se ahogaba por un exceso de tradición. De ahí que un sentido de penetración psicológica les anime a ir al fondo del alma regional, reflejada en la diversidad y personalidad de su pueblo, en la riqueza etnológica, en la nobleza campesina, en la sencillez popular.

Asturias, tardíamente introducida en la cultura urbana e industrial, continuaba siendo una zona eminentemente agrícola que se mantenía muy identificada con la imagen campesina. Esta mitificación de lo rural tenía, paralelamente, otra significación. La vida agrícola y ganadera se mostraba como radicalmente opuesta a las transformaciones culturales, económicas y políticas que el proceso de industrialización traía consigo y que se veían como violentas en exceso y poco respetuosas con las tradiciones. La modernidad era presentada como una amenaza para la pureza de la raza y del folklore autóctono; como un peligro para la recuperación y el mantenimiento de los valores de un pasado que estaban considerados como atributos propios e incuestionables del pueblo astur. De ahí la abundancia de representaciones de las costumbres populares con las que se persigue representar las esencias puras de la sociedad asturiana, en una palabra, su intrahistoria, utilizando la terminología de Miguel de Unamuno.

Se trata de la manifestación plástica de las costumbres ancestrales que defendía un tipo de arte castizo, en abierta reacción contra imagen de Castilla que desde el centro peninsular quería imponerse. Pintores como Ventura Alvarez Sala, Augusto Junquera, Manuel Arboleya o Telesforo Cuevas son un buen exponente de esta tendencia, apareciendo su obra repleta de variadas y pintorescas composiciones que reproducen la geografía asturiana, así como sus seres más humildes, siempre buscando el encuentro con la tierra, con la tradición, con las raíces y con la religiosidad más ancestral.

Con la llegada de Nicanor Piñole y de Evaristo Valle se hace evidente en el panorama asturiano una nueva e innovadora concepción regionalista.

\footnotetext{
5 Ver Pérez Rojas, J. y Garcia Castellón, M.: El siglo xx. Persistencias y rupturas. Sílex, Madrid, 1994, págs. 80.
} 
El ansia de modernización que ambos plantean se traducirá en la búsqueda de imágenes pictóricas novedosas y, sobre todo, en la incorporación de técnicas nuevas aprehendidas por medio del contacto con los movimientos de vanguardia parisinos a partir del impresionismo y sus distintas derivaciones postimpresionistas. Sus respectivos planteamientos estéticos se distancian de un realismo pintoresco, de la tópica visión de la Asturias del hórreo y de los aldeanos ataviados con el traje regional. Hay en sus creaciones una auténtica celebración del paisaje, de los encantos de un mundo lleno de color, pero siempre con un aliento impresionista intensificado: la despreocupada representación del mundo que los pintores franceses habían dado iba progresivamente a ser transformada en algo más emotivo, más dinámico y más consciente estilísticamente.

Más que construir el espacio mediante el color, estos pintores irán paulatinamente utilizándolo como expresión del sentimiento; lejos de un naturalismo aséptico y fotográfico, se esfuerzan por llegar a reflejar el alma del paisaje, encontrándonos ante nuestros ojos una pintura que va más allá de la mera reproducción de la realidad con fórmulas acostumbradas. Una reconstrucción personal de los estratos emocionales y físicos de la tierra materna, que puede parecernos en un primer golpe de vista un pretexto para la exploración en la psicología del hombre asturiano, en esos tipos humanos "naturales" y densos, irónicos y joviales, dotados de un poderoso instinto de sociabilidad.

En lo que se refiere a la obra de Evaristo Valle encontramos una singular plasmación del paisaje regional, tamizado por los aires de modernidad y de originalidad que le alejaban de la mayor parte de sus contemporáneos. Sus lienzos de paisaje están ejecutados sin alardes de técnica ni pesadeces de materia, exentos de enfática retórica compositiva. Renuncia a hacer uso de una técnica laboriosa y fiel de inventario visual, para optar por un tipo de factura más libre y espontánea. Rastrea los signos más ágiles del vivir asturiano en los ambientes rurales, en la mina o en el mar, dando lugar a la irrupción de composiciones técnicamente resueltas dentro de una tendencia al dibujo dinámico y expresivo, que combina con el empleo de la mancha plana, afianzada ésta por medio de despeinadas pinceladas de carácter abocetado. A ello une una búsqueda de depuraciones formales en la figura humana, poblando sus creaciones de personajes de esbeltas y alargadas proporciones, recortados con frecuencia sobre diluidos fondos de paisaje y envueltos en densas brumas de color. El paisaje en numerosas ocasiones es captado más allá de su plena desnudez, figurando en él seres animados de vida y pudiendo servir de fondo a extrañas y animadas escenas, envueltas en una especie de mágica penumbra. Las figuras se esfuman y despersonalizan para perderse en el conjunto como uno de sus elementos. 
Relatan estas composiciones no sólo estados atmosféricos, sino también pudieramos decir que estados anímicos. De ahí que abandone los paisajes desnudos para reproducir visiones que se ven pobladas por seres humanos, por figuras sorprendidas y psicológicamente distanciadas del espectador. Evita en sus composiciones lo vanalmente pintoresco, reflejando con grave dignidad la fisonomía y la vida de los distritos industriales y agrícolas de su tierra natal. No le interesan los ambientes descaracterizados, uniformes, impersonales, propios de las grandes concentraciones urbanas y de la burguesía que en ellas acampa. Por el contrario, persigue el hálito popular, las costumbres no falseadas, el ambiente íntegro y saturado de veracidad vernacular de las villas y aldeas.

Nicanor Piñole, más apocado y menos rebelde en su espíritu, pone la mirada insistentemente en sus obras sobre la vida cotidiana y habitual de las calles de su ciudad natal, Gijón. Observa la escena callejera impregnada de toda la humilde y cordial calidad del instante diario, con sus rincones portuarios, las vivencias de sus pescadores, los motivos de mercado. A estos argumentos se unen las plasmaciones festivas de las romerías asturianas, de las ferias aldeanas y, por supuesto, su amplia producción paisajística. A esta última dedicaba el pintor la mayor parte de su esfuerzo, dejándonos una prolífica labor encaminada a reflejar los aspectos más varios y diversos de su tierra. Son obras que sorprenden por su extraordinaria economía de medios, por la límpida sencillez de la ejecución plástica, muy parca en materia pictórica. Se trata de composiciones que, resueltas con una jugosa factura que reinterpreta las enseñanzas del impresionismo, están dotadas de un lirismo y de un aire de ensoñación que las convierte en visiones cargadas de visos de romanticismo. Se advierte en ellas su conocimiento directo del impresionismo francés y la eficaz asimilación de sus normas técnicas y lumínicas, tanto por la fragmentación de la pincelada por cuanto a la tendencia a las mezclas ópticas de abocetada y ágil figuración.

Pese a que la pintura relacionada con la problemática social había sido tímidamente recogida en las producciones de otros artistas plásticos regionales, como José María Uría y Uría, Nicolás Soria y Mariano Moré, estaba llamada a adquirir un amplio desarrollo con Evaristo Valle. Sus predecesores habian propendido a cultivar un tipo de composiciones anecdóticas, de argumento obrerista, en las que desaparecía todo animo de denuncia social. Las actitudes, los gestos, el atuendo, los detalles de todas estas obras se encontraban realizados según un criterio fijo heredero de la rígida normativa del academicismo y del arte oficial imperante. Eran lienzos en los que los trabajadores no aparecen sucios y cansados, sino limpios y con evidentes muestras de gozar de buena salud y 
visible alegría. Con frecuencia se disponen estos personajes en arreglo a esquemas teatrales, adoptando actitudes escénicas que eran acusadas por buena parte de la crítica de la época de falta de naturalidad y de efectismo.

Por el contrario, el proletariado urbano y minero es tratado por Evaristo Valle con una carga de profundización psicológica y un exacerbado realismo. Se impone en sus creaciones un realismo social del que están ausentes todo amaneramiento y afectación, caracterizándose por una aguda penetración en la vida de su tiempo. Son visiones personales y meditadas de la realidad asturiana de su tiempo, de una región en progresiva crisis de su sector minero, aquel que se había revelado como baluarte básico de su economía. Es Valle el pintor de los campesinos, de los parias, de los hombres y mujeres castigados por el trabajo y por las dificultades pecuniarias. Con creaciones como «En la cuenca minera" introduce al espectador en un mundo habitado de personajes de una intensidad sobrecogedora. Son obreros que viven constantemente angustiados, bajo la presión de sus patronos, aunque fortalecidos moralmente para hacer frente a su destino.

De acusado intimismo, son fruto de una descarga de rabia, de un sentimiento de dolor y hasta de frustración personal, donde el pintor se convierte en el cronista despiadado de las infamias y de la macroscópica estupidez de la sociedad, llevando a sus últimas consecuencias el proceso de mistificación de los viejos valores. Es el artista comprometido que tiende a incidir en la situación histórica, que lleva a cabo una lucha política, atacando y denunciando el resquebrajamiento de los cimientos morales de la colectividad; denunciando a los detentadores del orden social, con imágenes llenas de símbolos que se revelan inquietantes y peligrosas; amargas y casi desagradables. Centra su animadversión en una serie de personajes de los que reproduce sus aires triviales, su estupidez, su avaricia y su pretenciosidad. Son los poderosos de la tierra, los dueños de la superstición y de la perversión.

Acostumbrado como estaba el público a contemplar la pintura como algo evasivo, ajeno a sus vidas, estas obras de temática social pretendían, cuando menos, sorprender al espectador por medio de la representación descarnada de las injustas condiciones laborales de la clase obrera. En lugar de reflejar la realidad en función de la clase compradora, esto es, los sectores de la burguesía enriquecida, se preocupa Valle en pintar imágenes críticas que pongan de manifiesto la verdadera situación social. Hay en ellas una exaltación de la fuerza revolucionaria que encierra el trabajo, una feroz crítica de las consecuencias que traía consigo el amenazante 
capitalismo ${ }^{6}$. Costumbrismo y folklorismo son sustituidos en su plástica por un naturalismo sin concesiones, exento de idealismo y desarrollado en arreglo a un marcado contenido crítico.

Pero también en relación con esta singular pintura regionalista cultivada por Valle, podemos contemplar toda una amplia serie de visiones esperpénticas y de mascaradas; Carnavaladas que traducen una apreciación de la psicología humana que nos rememora el teatro de valleinclanesco. Creaciones pobladas de curiosos personajes, recreados a modo de acartonados muñecos llenos de superstición y de ironía. Como pintor un tanto enigmático y atormentado, de alma inquieta y rebelde, se nos revela en el aire extraño y desconcertante de estas Carnavaladas, donde su personalidad se hace manifiesta en la manera que tiene de llevar al lienzo tanto los aspectos de la realidad cotidiana como sus propias fantasías y donde atisba la belleza de las cosas a través de lo extraño. Notas de tragedia y de lo absurdo que, sin embargo, no llegan a la nota macabra, delirante y mísera que invade el universo esperpéntico de José Gutiérrez Solana, pese a los paralelismos que pudieran detectarse entre ambos.

Son las mascaradas una ocasión para que el pintor se evada del realismo para llegar a la deformación del reino de la fantasmagoría —un resurgir de los aquelarres de las brujas - y a la exuberancia lujuriosa del colorido. El hombre, viene a decimos irónicamente Valle, es un personaje del gran teatro del mundo, recogiendo toda una tradición de la pintura fantástica desde el Bosco hasta nuestros días, pasando por algunas de las figuras más inquietantes de la pintura contemporánea como el Goya de la Quinta del Sordo o el belga James Ensor. En estos temas burlescos los personajes que aparentemente se mueven como humanos son transportados por la máscara a un mundo irreal, en medio de la alegría y la tristeza general del desfile del Carnaval de la vida. La crudeza del pintor no hay que buscarlo tanto en la iconografía de estas obras como en el despiadado ofrecimiento de la interioridad del alma humana que nos presenta; en el repertorio de protagonistas que han eliminado la anécdota, que la han puesto entre paréntesis; en la monumentalidad de la figura plástica que trasciende la particularidad inicial de los personajes y de los acontecimientos. La expresión radica en las pasiones que revela cada rostro humano pero también en el gesto violento, en el dibujo ágil, la factura nerviosa, con abruptos acentos oscuros.

6 Es la estructura socioeconómica de la región asturiana, a partir del desarrollo de la moderna cultura industrial, funesta para el regionalismo tradicionalista con base campesina, la que propicia este tipo de manifestaciones pictóricas. En Bozal, V.: Historia del Arte en España. Istmo, Madrid, 1987, pág. 109. 
Son estas imágenes vallescas obras dotadas de una modernidad acuciante y que se conectan con ciertos esquemas expresionistas de pintura de vanguardia de la época. En un torbellino de colores, los personajes, hondos, sentidos, atormentados, hablan por sí mismos; el pintor los saca a la luz para dotarlos de autenticidad y prestancia. El fruto es toda una galería de individuos que, aunque reflejados desde una perspectiva de sátira e ironía, no pueden menos que adquirir tintes sombríos y hasta tétricos, Personajes que, alejándose cada vez más de lo anecdótico y de lo particular, respondiendo a un deseo de selección y de autocrítica, conforman una cosmogonía personal a la que se confiere valor de universalidad.

Para finalizar, la pintura regionalista asturiana, como hemos visto, encuentra su culminación y sus aportes más significativos e innovadores en las producciones de esos dos grandes creadores que han sido Valle y Piñole. Artistas que fueron capaces de superar los esquemas preponderantes en sus predecesores quienes más que al servicio de la emoción plástica y poética, estuvieron a merced de la anécdota, cuando no del tópico popular y mediatizada por él. De ahí la distancia entre este tipo de manifestaciones y la obra espiritual, intencionada, propia de aquellos dos puntales de la escuela pictórica astur. No sólo vemos en sus obras la personalidad pasajera y evolutiva de un pintor, sino más bien la inquebrantable personalidad fija y perenne de un verdadero artista plástico que adopta el oficio, la técnica, a sus necesidades expresivas; y conserva naturalmente su independencia creadora y personal. El artista que no ve a través de los clásicos, ni a través del clasicismo, sino que contempla con los ojos y la cabeza libres de soluciones prefabricadas y de esta manera llega a su mayor grado de originalidad.

\section{BIBLIOGRAFÍA}

Álvarez BuYLLA, B.: "La pintura asturiana», BCEA ,Vols. IV al VIII, Oviedo,1924-1926.

BARON, J.: La pintura asturiana durante la Restauración. Tomás García Sampedro, José Uría y Uría, Luis Menéndez Pidal y Juan Martínez Abades, Tesis Doctoral inédita, Universidad de Oviedo, 1989.

BarRoso VILlar, J.: La sociedad en la pintura tradicional asturiana, Museo de Bellas Artes, Servicio de Publicaciones del Principado de Asturias, Gijón, 1989.

Barroso VILlar, J.: «Artes de la modernidad en Asturias. La Pintura», Historia de Asturias, Prensa Asturiana, Oviedo, 1990.

BarRoso Villar, J.: Sociedad y pintura asturianas. Segunda mitad del siglo xx. Ayalga, Gijón, 1978.

BozAL, V.: El realismo plástico en España. De 1900 a 1936. Península, Madrid, 1967.

CID, C.: "Aproximación a las artes plásticas en Asturias", Primer Coloquio sobre Cultura y Comunidades Autónomas, Vic. Extensión Universitaria, Universidad de Oviedo, 1985.

ERICE, F.: La burguesia industrial asturiana (1885-1920). Silverio Cañada, Gijón, 1980. 
García Castellón, M.: El siglo xx. Persistencias y rupturas. Sílex, Madrid, 1994.

GAYA NuÑo, J.A.: "La pintura asturiana, ¿escuela regional o escuela universal?», BIDEA, n. 24,Oviedo, 1955.

GONZÁLEZ MUNIIZ, M.A.: "Asturias durante la Restauración (1874-1916)" Historia de Asturias, Edad contemporánea II, Vol. 8, Ayalga, Vitoria, 1981.

LAFUENTE FERRARI, E.: «Sobre el arte asturiano contemporáneo", BIDEA, n. ${ }^{\circ}$ 24, Oviedo, 1949.

MAINER, J. C.: Regionalismo, burguesía y cultura. A. Redondo, Barcelona, 1974.

MENÉNDEZ SUÁREZ, R.C.: El paisajismo en los pintores asturianos de la segunda mitad del siglo $x I X$ y la primera mitad del $x X$. Tesis de Licenciatura inédita, Universidad de Oviedo, 1974.

PENA López, M.C.C.: Pintura de paisaje e ideología. La generación del 98. Taurus, Madrid, 1983.

RuIz, D.: «E| 98 en Asturias. Apuntes para su estudio», BIDEA, n. ${ }^{\circ}$ 53, Oviedo, 1966.

URIA, J. y otros: Asturias y Cuba en torno al 98. Labor, Oviedo, 1994.

VILLA PAStUR, J: Historia de las artes plásticas asturianas. Ayalga, Salinas, 1979. 
